\title{
Does andropause exist?
}

\author{
Aldo Pende \\ Clinic of Internal Medicine 1, Department of Internal Medicine, University of Genoa, Italy
}

In comparison with female subjects who are characterized by a sudden decrease in gonadal hormonal activity with consequent disappearance of an easily detected function (menstruations), men physiologically present a very slow decline in testicular activity. For this reason it is difficult to give a clear definition of the male counterpart of menopause: andropause. As a matter of fact a PUBMED search for menopause gives much more hits than the term andropause (53,498 vs 427); in addition ICD-10 classification of diseases edited by the World Health Organization includes menopause but it does not accept andropause. Nevertheless these clinical issues are actively investigated due to a strong request of health, or at least fitness, in an attempt to reduce in part the undesired consequences of aging. ${ }^{1}$ Obviously andropause needs not to be confused with primary or secondary hypogonadism, situations in which testosterone replacement therapy is certainly indicated. ${ }^{2}$ In theory testosterone replacement therapy should contrast the subtle syndrome generally described as andropause and characterized by signs and syndromes such as loss of libido, erectile dysfunction, depression, loss of muscle mass (with various degrees): the main marker of this decline is a progressive decrease in testosterone serum levels, which begins as early as at 35 years of age with a drop of $1-1.5 \%$ on an

Correspondence: Aldo Pende, Clinic of Internal Medicine 1, Department of Internal Medicine, University of Genoa, IRCCS AOU San Martino - IST, viale Benedetto XV 6, 16132 Genoa, Italy.

Tel./Fax: +39.010.3537524

E-mail: apende@unige.it

Key words: andropause, testosterone, erectile dysfunction.

Received for publication: 7 March 2014.

Accepted for publication: 7 March 2014.

This work is licensed under a Creative Commons Attribution NonCommercial 3.0 License (CC BY-NC 3.0).

CCopyright A. Pende, 2014

Licensee PAGEPress, Italy

Italian Journal of Medicine 2014; 8:208-209

doi:10.4081/itjm.2014.501 annual basis until the values go below $3 \mathrm{mg} / \mathrm{L}^{3,4}$

Although the widespread use of sex steroids has raised many concerns about its safety, at least in females, some experts believe that testosterone can be proposed to elderly subjects under careful follow-up. The main reason for pursuing this approach is the possibility of an increased cardiovascular protection. ${ }^{5}$

In general human observational studies have suggested that male subjects with lower testosterone levels have a tendency to present a higher incidence of cardiovascular diseases (hypertension, coronary events). However testosterone replacement therapy seems to give quite modest advantages in terms of cardiovascular prevention. ${ }^{5}$

In this issue Pinna and Artom discuss these aspects reviewing all the available data in the literature. ${ }^{6}$ They start from their personal experiences in out-patient clinics for hypertension where, in a common effort with other centres in Piedmont and Liguria, they evaluate male subjects for erectile dysfunction trying to correlate the presence of this condition with possible causative factors. ${ }^{7}$ Again the most important relationship is between the sexual problem and the cardiovascular damage with the rational strategy to stress the preventive approach in case of presence of the erectile dysfunction. ${ }^{8}$

The authors correctly underline the absence of adequately designed trials for the evaluation of these relationships and this fact explains the reason for the difficulty to find comprehensive guidelines from academic institutions. Nevertheless the paucity of data should not induce the physician to forget the importance of a brief but complete clinical evaluation about erectile dysfunction using simple questionnaires: the quality of life of many male subjects can be heavily conditioned by this therapeutically improvable situation.

In conclusion at the present time a cautious approach is suggested to deal with the andropause and its clinical consequences: randomized controlled trial should give more definitive answers to the questions about sexual decline in male subjects which is certainly present. ${ }^{9}$ In the meantime the appropriate use of efficient drugs against erectile dysfunction, the avoidance of drugs which are potentially deleterious for sexual activity, and the possible search of an initial cardiovascular damage should be encouraged. 


\section{References}

1. Bhasin S, Travison TG, Jasuja R, et al. Testosterone and aging. In: Robertson RP, Halter JB, eds. Translational endocrinology and metabolism. Aging update. Vol. 2. Chevy Chase, MD: The Endocrine Society Publ.; 2011. pp 39-72.

2. Tajar A, Forti G, O'Neill TW, et al. Characteristics of secondary, primary, and compensated hypogonadism in aging men: evidence from the european male ageing study. J Clin Endocrinol Metab 2010;95:1810-8.

3. Schwarz ER, Phan A, Willis RD Jr. Andropause and the development of cardiovascular disease presentation - more than an epi-phenomenon. J Geriatr Cardiol 2011; 8:35-43.

4. Horstman AM, Dillon EL, Urban RJ, Sheffield-Moore $\mathrm{M}$. The role of androgens and estrogens on healthy aging and longevity. J Gerontol A Biol Sci Med Sci 2012; 67:1140-52.

5. Kaushik M, Sontineni SP, Hunter C. Cardiovascular disease and androgens: a review. Int J Cardiol 2010; 142:8-14.

6. Artom N, Pinna G. The erectile dysfunction as a cardiovascular risk factor. Ital J Med 2014;8:210-20.

7. Artom N, Pende A, Musso NR, et al. Prevalence of the erectile dysfunction in a population of hypertensive male subjects (multicentre study of the SIIA section PiemonteLiguria-Valle d'Aosta). High Blood Press Cardiovasc Prev 2013;20:222.

8. Manolis A, Doumas M. Sexual dysfunction: the "prima ballerina" of hypertension related quality-of-life complications. J Hypertens 2008;26:2074-84.

9. LeBrasseur NK, Lajevardi N, Miciek R, et al. Effects of testosterone therapy on muscle performance and physical function in older men with mobility limitations (The TOM Trial): design and methods. Contemp Clin Trials 2009;30:133-40. 